\title{
How arousal modulates memory: Disentangling the effects of attention and retention
}

\author{
TALI SHAROT and ELIZABETH A. PHELPS \\ New York University, New York, New York
}

\begin{abstract}
Emotion may influence memory both by altering attention and perception during encoding and by affecting memory retention. To date, studies have focused on the enhancement of memory consolidation by arousal. However, they have failed to rule out a role for attention. To specifically link memory enhancement of arousing material to modulation of memory retention, we examined recognition of neutral and arousing words at two time points and under conditions that manipulate attention during encoding. Participants were briefly presented with an arousing or neutral word at the periphery, while fixating on a central word. Recognition of peripheral words was assessed either immediately or after $24 \mathrm{~h}$. Whereas recognition of neutral words became worse over time, recognition of arousing words remained the same and was better than neutral word recognition at delay. The results indicate that arousal supports slower forgetting even when the difference in attentional resources allocated to stimuli is minimized.
\end{abstract}

Memory enhanced with emotion has been documented across a range of memory studies including field studies (e.g., Bohannon, 1988) and laboratory studies, with stimuli such as emotionally charged stories (e.g., Heuer \& Reisberg, 1990), film clips (e.g., Cahill et al., 1996), words (e.g., LaBar \& Phelps, 1998), and pictures (e.g., Bradley, Greenwald, Petry, \& Lang, 1992; Christianson \& Fallman, 1990). It has been suggested that emotion may influence memory in two different ways, by altering attention and perception during encoding (Christianson \& Loftus, 1991; Reisberg \& Heuer, 1992) and by affecting memory retention (Kleinsmith \& Kaplan, 1963).

Examination of the neural mechanisms underlying memory of emotional events has predominantly focused on the latter, and suggests that adrenal stress hormones related to emotional arousal are crucial for allowing the significance of an event to enhance hippocampal-dependent memory consolidation of that experience (McGaugh, 2000). The amygdala, a small almond-shaped structure in the medial temporal lobe adjacent to the hippocampus, is critical in mediating the influence of stress hormones that activate adrenergic receptors on memory strength (McGaugh, 2000). Amygdala lesions block the strengthening effects of these modulators on memory consolidation, as does posttraining infusion of $\beta$-adrenergic receptor antagonists

This study was supported by the National Institutes of Health Grant MH62104 to E.A.P. We thank Marisa Carrasco for her assistance in the design of the experiment, Mauricio Delgado and Barry Cohen for helpful comments on a previous draft of this article, Nonso Enekwechi and Dani Korya for their help in data collection, and Melinda Miller, Ben Holmes, and Laura Thomas for programming assistance. Correspondence should be addressed to E.A. Phelps, Department of Psychology, 6 Washington Place, Room 863, New York University, New York, NY 10003 (e-mail: liz.phelps@nyu.edu). into the amygdala (Liang, Juler, \& McGaugh, 1986), a strong indication that the enhancement effect occurs after initial encoding.

Findings from human studies support the notion that memory is influenced by emotional arousal via amygdala activation and the adrenergic system. Adrenergic receptor antagonists have been shown to block the modulation of memory by emotional arousal in humans (Cahill, Prins, Weber, \& McGaugh, 1994). Neuroimaging studies have reported a correlation between long-term memory of emotionally arousing stimuli and degree of amygdala activation during encoding (Cahill et al., 1996; Hamann, Ely, Grafton, \& Kilts, 1999), as well as enhanced amygdala activation during retrieval of emotional items (Dolan, Lane, Chua, \& Fletcher, 2000). Furthermore, emotional arousal fails to enhance long-term memory of arousing words in patients with selective lesions of the amygdala (LaBar \& Phelps, 1998).

However, studies conducted with humans have not been able to rule out a role for attention in the enhancement of memory retention that occurs with emotional arousal. Unlike studies conducted with nonhuman animals, which have shown an effect on later memory by postencoding arousal or pharmacological manipulation, studies with humans have manipulated arousal at encoding and failed to control for an effect on attention. In two studies (Cahill \& Alkire, 2003; Cahill, Gorski, \& Le, 2003), an endogenous stress hormone was administered after encoding, and the findings revealed that this manipulation enhanced later memory only for stimuli that were already arousing by their own properties. Thus, modulation of attention at encoding could not be ruled out. In addition, most of these studies have examined memory at only one point in time and have failed to determine whether the effect of emotion on memory is enhanced over time. Without examin- 
ing memory at different time points, immediately after encoding as well as after a delay, and without looking at memory of emotional material under conditions that control for attention, we are unable to specifically link memory enhancement of arousing material to modulation of hippocampal-dependent memory consolidation in humans.

The aim of this study was to explore the interaction between the two elements - attention and retentionthat influence memory of arousing stimuli, and to examine whether they are both necessary for slower forgetting of such stimuli. We will begin with a review of the effects of arousal on attention and on memory storage.

\section{Effects of Arousal on Attention}

There are a few ways by which arousal can affect attention and thereby influence encoding. The first is by modulating the selectivity of attention. Easterbrook (1959) proposed that arousal will lead to the "narrowing of attention - that is a decrease in the span of cues to which an organism is sensitive. When observing an emotional event, attention will be focused primarily on the arousing details of the stimulus, resulting in better encoding of those details and impaired encoding of less relevant details. In an effort to examine eye movements as an indicator of the location of overt attention, studies have indeed shown that an emotional slide elicited eye movements consistent with attentional narrowing (Loftus, Loftus, \& Messo, 1987). Such selectivity could lead to better memory for central details of an arousing event at the expense of memory for peripheral details (Burke, Heuer, \& Reisberg, 1992; Christianson \& Loftus, 1991). Adolphs, Denburg, and Tranel (2001) reported that bilateral damage to the amygdala resulted in inferior memory for gist of aversive scenes but better memory for visual details of those scenes, suggesting that the amygdala may play a role in filtering relevant information from stimuli that signal threats during encoding. A second way by which arousal can influence attention is by enhancing attentional dwell time on the arousing stimuli and delaying the disengagement component of attention (Fox, Russo, Bowles, \& Dutton, 2001).

Arousal may also modulate attention by allowing such stimuli to be processed more efficiently (Hansen \& Hansen, 1988), achieving awareness with less attentional resources. Anderson and Phelps (2001) have shown that under settings of limited attention for normal perceptual awareness (the attentional blink), normal participants showed enhanced perception of aversive arousing words compared with nonarousing words. In fact, it has been suggested that arousing stimuli can be processed even when the stimuli appear outside the focus of attention and without conscious awareness (Christianson, 1992; Öhman, Estevens, \& Soares, 1995). Viewing an arousing stimulus for a very brief time evokes an automatic assessment of it (Bargh, Chaiken, Govender, \& Pratto, 1992). Heightened physiological measures, which reflect an individual's emotional response, arise even when the stimulus is not consciously recognized. Masked fear-conditioned faces, for example, evoke skin conductance changes in participants, even if they later fail to report perceiving those faces (e.g., Öhman et al., 1995). Brain imaging studies have also shown that processing of arousing stimuli can occur when attention is directed to a different task (Vuilleumier, Armony, Driver, \& Dolan, 2001) and in patients with spatial neglect (Vuilleumier \& Schwartz, 2001). Christianson (1992) proposed that there may be elements inherent in emotional stimuli that cause them to be processed by automatic, apparently "preattentive," mechanisms, thus facilitating responses toward such meaningful stimuli.

Ochsner (2000) has suggested that by modulating the selectivity of attention, enhancing attentional dwell time, and allowing arousing stimuli to be processed more efficiently, the distinctiveness with which arousing stimuli are encoded is strengthened, resulting in more accurate memory of that stimuli. Although such modulations of attention and perception by arousal may affect long-term memory, one would also expect to see the results of this influence on memory at short delays. Indeed, better memory for arousing stimuli, as compared with neutral stimuli, has been reported both for immediate recollection (e.g., Christianson, 1984; Christianson, Loftus, Hoffman, \& Loftus, 1991; Loftus et al., 1987) and for long-term retention (e.g., Cahill et al., 1996; LaBar \& Phelps, 1998).

\section{Effects of Arousal on Memory Storage}

A number of studies suggest that the effect of arousal on memory is enhanced following a delay; whereas memories for neutral stimuli decrease over time, memories for arousing stimuli remain the same or improve over time (e.g., Baddeley, 1982; Kleinsmith \& Kaplan, 1963; LaBar \& Phelps, 1998; Levonian, 1966; Walker \& Tarte, 1963). Research on the neural mechanisms of memory for arousing events indicates that arousal leads to enhanced long-term memory of stimuli by altering hippocampal consolidation of these memories (Cahill, Babinsky, Markowitsch, \& McGaugh, 1995; Hamann et al., 1999; McGaugh, 1992; Packard \& Teather, 1998). It has been suggested that the slow consolidation of memories serves an adaptive function by enabling neurohormonal processes triggered by an arousing stimulus to modulate memory strength (McGaugh, 2000). In a classic study, Kleinsmith and Kaplan (1963) found that after a 1-week delay, participants recalled significantly more numbers paired with arousing words than with nonarousing words. They also found that the reverse was true for participants given an immediate test. Other studies since have shown a similar pattern of results (e.g., Baddeley, 1982; Levonian, 1966; Walker \& Tarte, 1963). Although the significantly higher recognition rates of numbers paired with arousing words versus neutral words in the delay test can be explained by emotional memory consolidation mechanisms (McGaugh, 2000 ), the reason underlying the poorer recognition rates for numbers paired with arousing words found in the immediate test is unclear. 
As consolidation of memory occurs over a period of time, the effects of arousal on enhanced memory consolidation will be apparent only following a delay. The exact duration of time in which consolidation takes place is uncertain. The behavioral affects may be evident as soon as $1 \mathrm{~h}$ after encoding (LaBar \& Phelps, 1998) and are expected to be visible at least $24 \mathrm{~h}$ later (e.g., Adolphs, Tranel, \& Denburg, 2000; Gallagher \& Kapp, 1981; Vazdarjanova \& McGaugh, 1999). If arousal were to influence memory for emotional stimuli via strengthening hippocampal consolidation alone, one would expect to see better memory for such stimuli relative to neutral stimuli after a delay, but not immediately after encoding.

\section{Interaction Between the Effects of Arousal on Encoding and on Memory Storage}

Although it seems probable that arousal influences memory both by mediating acquisition of arousing stimuli (Anderson \& Phelps, 2001; Christianson \& Loftus, 1991) and by modulating memory consolidation (Cahill et al., 1996; LaBar \& Phelps, 1998), it is unclear how these mechanisms interact and whether they are both necessary for enhanced memory of arousing stimuli.

From research with nonhuman animals, it is clear that modulation of attention is not necessary for enhanced memory retention. Studies in rats demonstrate that posttraining systemic injection of epinephrine enhances longterm memory (Packard \& Teather, 1998). Epinephrine is an adrenal medullary hormone released in the bloodstream when a person is in an aroused state and is one means by which arousal is thought to influence hippocampal consolidation (McGaugh, 1992). The poststimulus drug administration obviously excludes effects on acquisition or retrieval because the drug's influence occurs after training is completed, and the drug is inactive by the time of retrieval, hence supporting the notion that arousal can influence memory by affecting consolidation.

If one were to argue that attention was the primary mechanism underlying the superior memory of arousing stimuli relative to neutral stimuli, one would expect to see better memory for these stimuli, both immediately and after a delay. Given this assumption, however, one would have a difficult time interpreting Kleinsmith and Kaplan's (1963) results, showing an advantage for numbers paired with arousing words over those paired with neutral words only at delayed test, but not at immediate test. In some respects, by looking at cued recall for numbers paired with arousing or nonarousing words, Kleinsmith and Kaplan were examining memory for a neutral peripheral detail (the paired numbers) of an event. Although participants were given enough time to study the pairs, it is possible that attention was captured to a larger degree by the arousing words than by the neutral words. The immediate result was a tradeoff for memory of the numbers paired with these words: better memory for numbers paired with nonarousing words than for those paired with arousing words. However, at the delay test, for which the results were reversed, the effect of enhanced consoli- dation became apparent and may have overshadowed those of attention.

Efforts have been made in the past to study memory of arousing stimuli per se (rather than those paired with arousing stimuli) under conditions of restricted attentional resources, by utilizing short exposure times (Christianson et al., 1991; Ochsner, 2000). These studies revealed that under such conditions, arousing stimuli are still remembered better than neutral stimuli. However, these studies (Christianson et al., 1991; Ochsner, 2000), like many others (Christianson, 1984; Christianson \& Loftus, 1991; Christianson et al., 1991; Clifford \& Hollins, 1981; Libkuman, Nichols-Whitehead, Griffith, \& Thomas, 1999; Wessel, van der Kooy, \& Merckelbach, 2000), examined memory for arousing stimuli only at one point in time, usually immediately after encoding, and were thus unable to study the long-term modulation of memory by arousal.

It has been shown that processing of the arousing properties of a stimulus can occur when attention is focused on a different task (Vuilleumier et al., 2001), but do such encoding conditions allow for enhanced retention? The present study tests for the first time whether arousal can support long-term memory of a stimulus even when overt attention is not focused on the arousing to-be-remembered stimulus. In contrast to Kleinsmith and Kaplan's (1963) study, this study examines memory for stimuli that are arousing for their own properties (i.e., arousing words rather than numbers paired with arousing words). We investigate how the arousing property of a word influences the retention of that word, when overt attention is focused elsewhere during encoding. To date, no attempt has been made to study memory of arousing stimuli presented in the visual field periphery. The design of our study allows us to examine the effects of overt attention and retention interval on recognition rates of arousing and neutral stimuli.

In Experiment 1, participants were very briefly exposed to a neutral word at the center of the screen and at the same time to either an arousing or a neutral word at the periphery. To engage attention at the center, participants were asked to fixate the central word and to make a frequency judgment regarding that word. Recognition for all words was assessed either immediately or after $24 \mathrm{~h}$.

\section{EXPERIMENT 1}

\section{Method}

Participants. The participants were 50 undergraduates at New York University ( 29 females and 21 males, between 18 and 28 years of age). The participants were randomly assigned to either the immediate test condition $(n=25)$ or the delayed test condition $(n=$ 25). All the participants provided informed consent and were either paid or received course credit for their participation.

Materials. Words were chosen from the list of words used by LaBar and Phelps (1998). All words were 4-6 letters long, their size on the screen was $5 \times 1 \mathrm{~cm}$, and peripheral words were centered at $5^{\circ}$ of visual angle, $5 \mathrm{~cm}$ from fixation. (See the Appendix for all words used in the study.) Since word norms are not available for 
most of the arousing words used in this study, 15 undergraduates from New York University, drawn from the same population as were the other participants in this study, rated all words for arousal, valence, and familiarity. Word familiarity was rated on a scale from 1 (not at all familiar) to 7 (very much familiar). No difference was found in the ratings of familiarity for neutral $(M=5.7, S D=0.62)$ and arousing $[M=5.5, S D=0.39 ; t(48)=1.35, p>.05]$ words. It has been argued that subjective familiarity ratings (e.g., Gernsbacher, 1984; Gilhooly \& Logie, 1980) and subjective frequency ratings (Balota, Pilotti, \& Cortese, 2001) serve as better reflections of the relative frequency of exposure to a word than do objective frequency counts.

Word valence was rated on a scale from 1 (positive) through 4 (neutral) to 7 (negative). Neutral words were rated as neutral $(M=$ $3.4, S D=0.42)$ and arousing words as negative $[M=5.6, S D=0.88$; $t(48)=11.05, p<.001]$. Arousal was rated on a scale from 1 (not at all arousing) to 7 (very much arousing). Neutral words had lower arousal ratings $(M=1.96, S D=0.42)$ than did negative words $[M=$ 3.62, $S D=0.49 ; t(48)=12.93, p<.001]$.

Preceding word rating, skin conductance responses (SCRs) to the words were recorded from participants in a pilot study, drawn from the same population as were the other participants in this study, using the same paradigm as in this experiment. This was done to ensure that the stimulus words caused physiological arousal under this paradigm. SCR is a phasic measure of eccrine sweat gland activity, a dependable autonomic indicator of sympathetic nervous system excitation (Venables \& Christie, 1973). SCRs were recorded from the third and fourth fingers of the participants' nondominant hands and scored according to conventional criteria (for details on the psychophysiological recording and analysis, see LaBar, LeDoux, Spencer, \& Phelps, 1995). The participants produced larger SCRs to the arousing words than to the neutral words $[t(16)=1.93, p<.05$, onetailed]. These findings, together with the arousal ratings, suggest that the arousal manipulation at encoding was effective in producing subjective and physiological arousal.

Design and Procedure. During encoding, the participants sat $57 \mathrm{~cm}$ from a computer screen. There were 16 trials in which they were asked to fixate a neutral word at the center of the screen, and at the same time either a neutral word ( 8 trials) or an arousing word ( 8 trials) appeared at one of the corners of the screen $5 \mathrm{~cm}$ from the center, $5^{\circ}$ from fixation. The intertrial interval was $10 \mathrm{sec}$, and the stimulus duration was $250 \mathrm{msec}$. Given that it takes about $250 \mathrm{msec}$ for a target-directed saccade to be initiated when no other attentionconsuming task is presented (e.g., Carpenter, 1988; Mayfrank, Kimmig, \& Fischer, 1987), this stimulus duration minimizes the probability of saccadic eye movements to the word in the periphery in the present design. A pilot study revealed that shorter stimulus durations (e.g., $180 \mathrm{msec}, 200 \mathrm{msec}$ ) resulted in a floor effect for word recognition under all conditions. To engage attention at the center, the participants were asked to fixate the central word and to indicate how often they encountered that word in the English language on a scale from 1 (rarely) to 5 (often) by striking a key (1-5) on the keyboard.

After the encoding phase, the participants in the delay condition were told to return to the lab the following day in order to participate in a similar study. The participants in the immediate condition began the test phase approximately $3 \mathrm{~min}$ after the end of the encoding phase, following instructions for the test phase. Informal debriefing revealed that the participants in both the delay and immediate conditions did not anticipate a memory test. Although enhanced memory of arousing words may be apparent at a retention interval shorter than $24 \mathrm{~h}$, previous studies have shown that the effects of consolidation should be evident at least $24 \mathrm{~h}$ after learning has taken place (e.g., Gallagher \& Kapp, 1981; Vazdarjanova \& McGaugh, 1999).

Either immediately or after $24 \mathrm{~h}$, a surprise two-forced-choice recognition test was given. The participants went through 32 test trials in a random order, with the trials including all central and peripheral words. In each trial, two words were shown on the screen, one old and one new. The participants were asked to indicate which of the two words was shown in the first part/day of the experiment, by pressing " 1 " on the keyboard if the word shown on the left was the "old" word, or "9" if the word shown on the right was the "old" word. Word pairs were matched for frequency and arousal (see the Appendix for target words and matched foils).

Recognition of central words was found to be at ceiling both at the immediate (97\%) and delay (96\%) tests, suggesting that participants were indeed engaged with the central task. Recognition scores of 5 participants who recognized fewer than 14 of the $16(87.5 \%)$ central words correctly were not used, to control for the possibility that they did not fixate the central words at all times, as instructed, and thus correctly recognized a lower proportion of the central words.

\section{Results}

Recognition scores were subjected to an analysis of variance with retention interval (immediate vs. delay) as a between-subjects variable and word type (arousing vs. neutral) as a within-subjects variable. To control for Type I errors in testing simple main effects, we used a familywise Bonferroni adjustment. Because each of our factors had two levels, we used an alpha of .025 to test each of our simple main effects (Keppel, 1991).

As is illustrated in Figure 1, recognition scores for peripheral words were characterized by a reliable interaction of word category $\times$ retention interval $[F(1,48)=$ $7.66, p<.01]$. The results of a within-subjects $t$ test indicate that after $24 \mathrm{~h}$, recognition of arousing words was significantly higher than that for neutral words $[t(24)=$ $2.56, p<.02]$. An independent sample $t$ test showed that recognition for neutral words was better at immediate test than at delayed test $[t(48)=2.34, p<.025]$. All other comparisons were found to be not significant.

\section{Discussion}

The findings of Experiment 1 suggest faster forgetting for nonarousing words than for arousing words, showing a reliable word type (arousing vs. neutral) $\times$ retention interval interaction, like that reported by Kleinsmith and Kaplan (1963). The results are also consistent with previous findings that arousing stimuli are recognized more accurately than nonarousing stimuli after a delay (e.g., Cahill et al., 1995; Ochsner, 2000). These findings go beyond previous ones in demonstrating that arousal can support memory retention of a stimulus, even when that stimulus is presented in the visual field periphery. Better recognition of arousing words over neutral words was evident only at delayed test, and not at immediate test, supporting the notion that the primary mechanism underlying this superior recognition is an effect of retention.

\section{EXPERIMENT 2}

In order to engage overt attention at the center of the screen, the participants were asked in Experiment 1 to fixate a central word, which appeared briefly together with the peripheral word, and to make a frequency judg- 


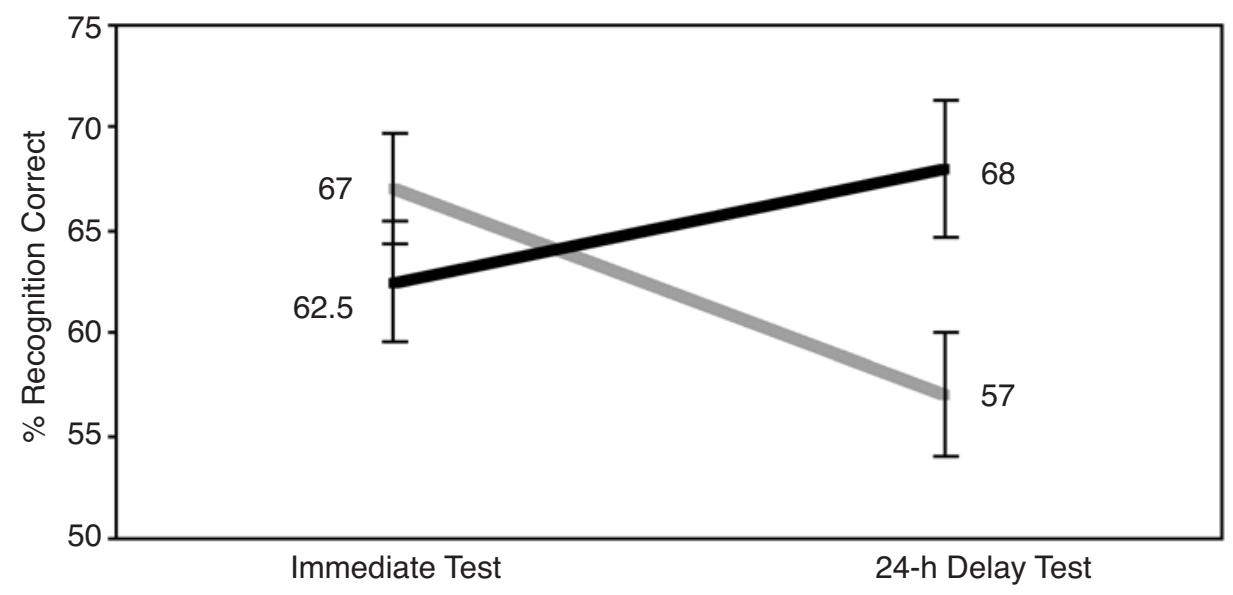

Neutral Words

Arousing Words

Figure 1. Experiment 1: Recognition rates for peripheral words at immediate and delayed tests. One word (either neutral or arousing) was presented at the periphery at the same time as a neutral word was presented at the center of the screen. Brackets represent standard errors of the means.

ment regarding the central word. To minimize possible differential covert shifts of attention, which may be more frequent for arousing words than for neutral words, in Experiment 2 the participants were exposed simultaneously to both an arousing word and a neutral word at the periphery, while they were asked to fixate a neutral word at the center. Such demanding conditions may make selective shifts less likely. Furthermore, assuming that the neutral-peripheral and arousing-peripheral words were now competing for a very limited attentional resource (they appeared simultaneously, rather than on separate trials, as in Experiment 1), if an attention mechanism were underlying the pattern of results in Experiment 1, a relatively larger difference between recognition rates would be expected in the delayed test in Experiment 2, compared with Experiment 1, as well as higher recognition rates for arousing words over neutral words at the immediate test.

\section{Method}

Participants. The participants were 50 undergraduates at New York University ( 33 females and 17 males from 18 to 28 years of age) assigned to either the immediate test condition $(n=25)$ or the delayed test condition $(n=25)$.

Materials. Materials were the same as in Experiment 1 (see Method section in Experiment 1).

Design and Procedure. The method for Experiment 2 was identical to that of Experiment 1, except that at the periphery a neutral word and an arousing word appeared simultaneously either vertically or horizontally to one another at two of the four corners of the screen, $5 \mathrm{~cm}$ from the center, at $5^{\circ}$ from fixation. As in Experiment 1 , a neutral word was presented at the center of the screen at the same time. In Experiment 2, the participants went through only 8 trials, but they were exposed to a total of 16 peripheral words as in Experiment 1 ( $16=8$ trials $\times 2$ peripheral words $)$. As in Experiment 1 , recognition of central words was at ceiling $(99 \%)$ for both the immediate and delayed tests, suggesting that the participants were indeed engaged with the central task. Recognition scores of 3 participants who recognized fewer than 7 of the $8(87.5 \%)$ central words correctly were not used (see Method section in Experiment 1, for justification).

\section{Results}

Data analysis was the same as in Experiment 1 (see Results section in Experiment 1).

As in Experiment 1, recognition scores were characterized by a reliable interaction of word category and retention interval $[F(1,48)=5.22, p<.05$; see Figure 2]. No pairwise comparisons were found to be significant. The $95 \%$ confidence interval for mean recognition rates of the arousing words in the immediate test $\left(\mu_{\text {lower }}=46.54 \%\right)$ and of the neutral words at delay test $\left(\mu_{\text {lower }}=48.73 \%\right)$ indicate that in both these cases, recognition rates were not significantly different from chance (50\%). However, $95 \%$ confidence interval for mean recognition rates of both neutral words at immediate test $\left(\mu_{\text {lower }}=56.2 \%\right)$ and arousing words at delay test $\left(\mu_{\text {lower }}=54.5 \%\right)$ were significantly above chance.

When the results of Experiment 2 were compared with those of Experiment 1, no three-way interaction (time of test $\times$ type of word $\times$ number of words in the periphery) was found. We thus collapsed the results from Experiments 1 and 2. Overall collapsed recognition scores were characterized by a reliable interaction of word category $\times$ retention interval $[F(1,98)=12.44, p<.01$; see Figure 3], as also found separately in both Experiments 1 and 2. To control for Type I errors in testing simple main effects, we used a familywise Bonferroni adjustment, setting alpha to .025 to test each of our simple main effects (Keppel, 1991). A within-subjects $t$ test indicated that at delayed test, recognition rates of arousing words were significantly higher than those of neutral words 

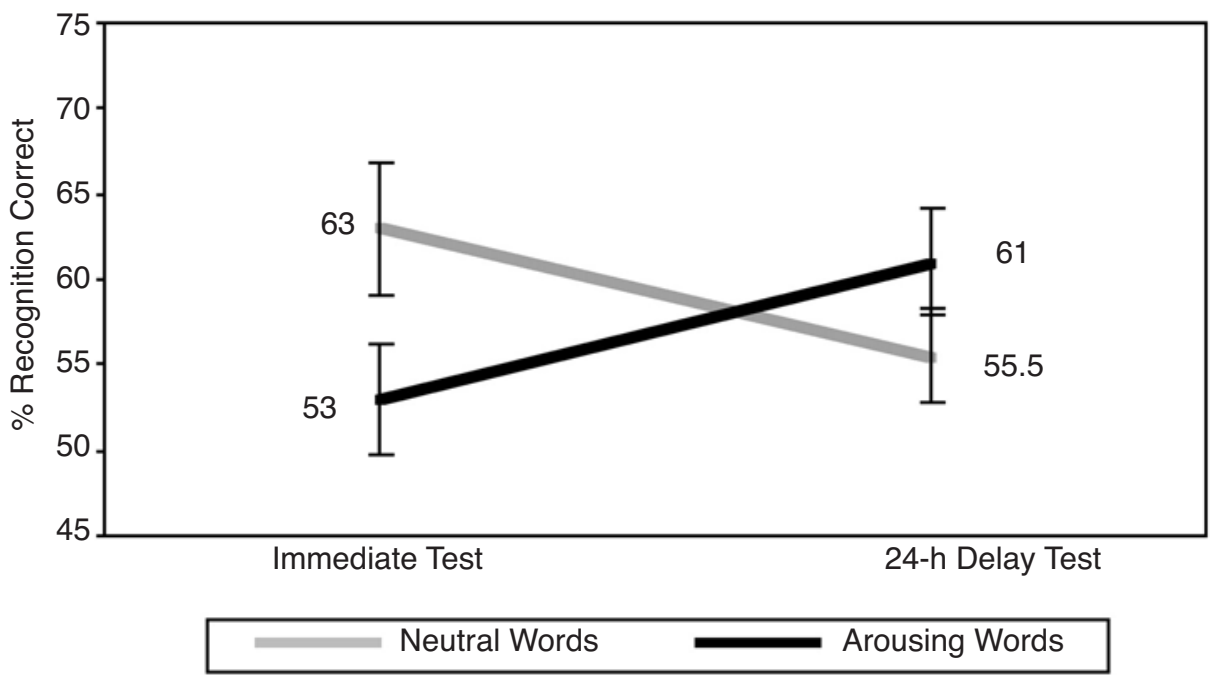

Figure 2. Experiment 2: Recognition rates for peripheral words at immediate and delayed tests. Two words (neutral and arousing) were presented simultaneously at the periphery at the same time as a neutral word was presented at the center of the screen. Brackets represent standard errors of the means.

$[t(48)=2.86, p<.01]$. At immediate testing, recognition rates of neutral words were marginally higher than those of arousing words $[t(48)=2.19, p=.033]$. An independent sample $t$ test revealed that neutral words were recognized better at immediate test than at delayed test $[t(48)=2.75, p<.01]$. For arousing words, there was a marginally significant effect for better recognition at delayed test than at immediate test $[t(48)=2.11, p=.045]$.

Overall recognition rates were lower in Experiment 2 $(M=58.1 \%, S D=1.6)$, when the participants were exposed to two stimuli in the periphery at the same time, than in Experiment $1[M=63.6 \%, S D=1.6 ; F(1,98)=5.88$, $p<.01]$.

\section{Discussion}

The somewhat low performance rates in Experiment 2, as compared with those in Experiment 1, suggest that the task in Experiment 2 was more demanding than that in Experiment 1. Nevertheless, even when one minimizes possible differential covert shifts of attention, the results demonstrate once again a reliable word type (arousing vs. neutral) $\times$ retention interval interaction (see Figure 2), with no three-way interaction between the results of Experiments 1 and 2. When the results of Experiments 1 and 2, were collapsed, recognition rates of arousing words at delayed test were higher than recognition rates of neutral words, as in Experiment 1. Also, recognition rates of arousing words revealed an enhancement trend over time. These findings are consistent with the notion that arousal leads to enhanced long-term memory $(\mathrm{Ca}-$ hill et al., 1995; LaBar \& Phelps, 1998; McGaugh, 1992; Packard \& Teather, 1998). Additionally, there was a trend at the immediate test for recognition rates of neutral words to be higher than those of arousing words, and there was marginally better recognition of arousing words at delayed test than at immediate test, in accord with Kleinsmith and Kaplan's (1963) findings. Possible inhibition or interference effects that may underly these trends are reviewed in the General Discussion section.

\section{EXPERIMENT 3}

In Experiments 1 and 2, a neutral word was presented at the center of the screen, where overt attention was focused. Thus, the participants were aroused only when the word at the periphery was arousing. In Experiment 3, we asked whether a pattern of recognition rates similar to that found in Experiments 1 and 2, would emerge if the participants were to encounter an arousing word, instead of a neutral one, at the center of the screen. As in Experiment 1, at the periphery either a neutral word or an arousing word was presented. In this experiment, attention should be engaged to an even larger extent by the central word because arousing stimuli, once attended to, have been shown to engage attention to a greater degree than neutral stimuli, increasing attention dwell time at that location and influencing the disengagement component of attention (Fox et al., 2001).

\section{Method}

Participants. The participants were 50 undergraduates at New York University ( 32 females and 18 males between 18 and 28 years of age) assigned to either the immediate test condition $(n=25)$ or the delay test condition $(n=25)$.

Materials. Materials were the same as in Experiments 1 and 2.

Design and Procedure. The method for Experiment 3 was identical to that of Experiment 1 except that at the center of the screen an arousing word was presented rather than a neutral word as in Experiments 1 and 2 .

As in Experiments 1 and 2, recognition of central words was found to be at ceiling both at the immediate $(98.5 \%)$ and delayed $(98 \%)$ tests, suggesting that participants were indeed engaged with the central task. Recognition scores of 4 participants who recog- 


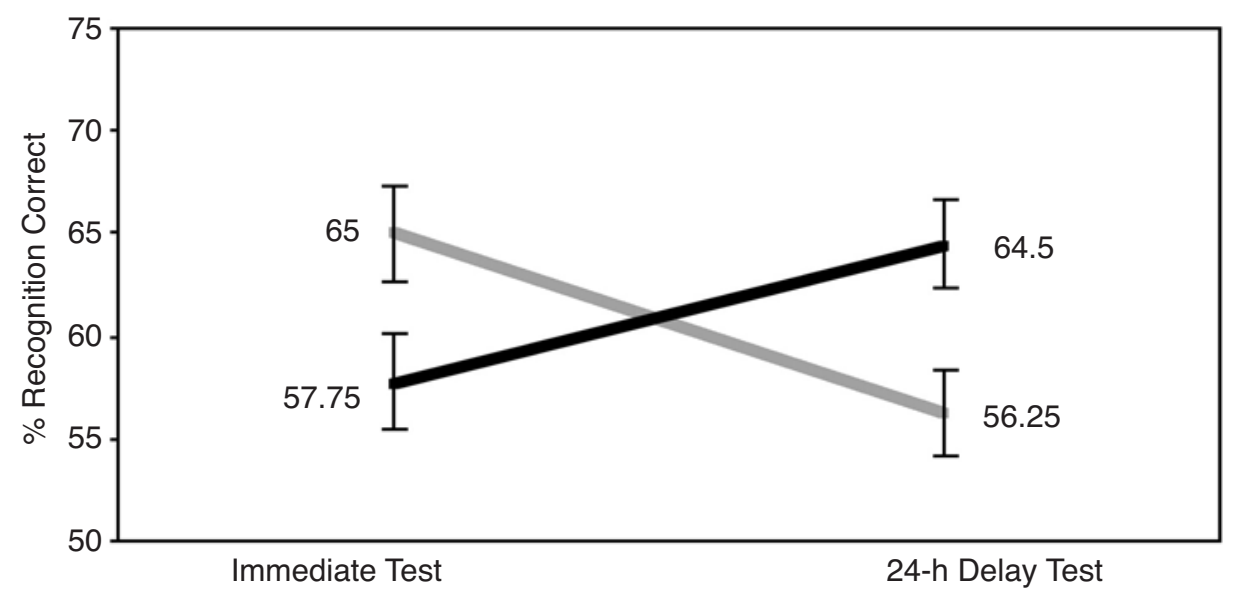

Neutral Words

Arousing Words

Figure 3. Experiments 1 and 2: Collapsed recognition rates for peripheral words at immediate and delayed tests. Brackets represent standard errors of the means.

nized fewer than 14 of the $16(87.5 \%)$ central words correctly were not used (see Method section of Experiment 1 for reasoning).

\section{Results}

Data analysis was the same as in Experiment 1 (see Results section of Experiment 1).

Recognition scores for peripheral words did not reveal a significant interaction of word category (neutral vs. arousing $) \times$ retention interval $[F(1,48)=2.41, p=.127]$. The results of a within-subjects $t$ test indicate that after $24 \mathrm{~h}$, but not immediately, recognition of arousing words was significantly higher than that for neutral words $[t(24)=2.97, p<.01]$. An independent sample $t$ test shows that recognition for neutral words was better at the immediate test than at the delayed test, where recognition rate was at chance $[M=49.5 \%, t(48)=2.575, p<.025]$. Recognition for arousing words at the immediate test did not differ from recognition at the delayed test.

When the results of Experiment 3 were compared with those of Experiment 1, no three-way interaction (time of test $\times$ type of word at periphery $\times$ type of word at center) was found, nor was a main effect of type of central word found.

\section{Discussion}

In Experiment 3 an arousing word, instead of a neutral word, was placed at the center of the screen. In accord with results of Experiments 1 and 2, whereas recognition for neutral words decreased over time, recognition for arousing words remained unchanged, and higher recognition rates for arousing peripheral words than for neutral peripheral words were revealed at delayed test. These results suggest that even when the processing of an arousing stimulus occurs while overt attention is focused on a task in a different location, there is better memory re- tention of that stimulus than there is of a neutral stimulus. Also consistent with Experiments 1 and 2, neutral words were recognized better at immediate test than at delayed test, suggesting in this case that any arousal caused by the central word did not have an enhancing effect on retention of the peripheral neutral word. In contrast to Experiments 1 and 2, no crossover interaction of word category (arousal vs. neutral) $\times$ retention interval was found (see Figure 4).

Interestingly, the results of Experiment 3 reveal a numerically higher recognition rate for arousing words than for neutral words at immediate test, rather than a lower recognition rate, as in Experiments 1 and 2. It seems that the presence of an arousing word at the locus of attention throughout all trials in Experiment 3 had a distinct immediate beneficial influence on memory for the peripheral arousing words relative to the peripheral neutral words.

One possible explanation for this trend is the effect theory (Hochberg, 1978; Neisser, 1976), which states that the greater congruency a stimulus has with the internal context of the system, the more processing it will receive; thus, the arousing peripheral word received more processing than did the neutral peripheral word, because it matched the central word both emotionally and semantically. The word at fixation set a specific semantic and arousing context on all the trials, which enhanced processing for the arousing peripheral word, leading in turn to better immediate memory. An alternative account of this trend concerns the match between the state of the participant at times of study and test. It is suggested that people recollect more accurately when they are in the same internal state at test as at study (see Balch, Myers, \& Papotto, 1999 for a review). In Experiment 3, the participants processed arousing words at fixation during en- 
coding on all trials, but at test they were presented with arousing stimuli only when asked to recognize the emotional words. Thus, a greater internal state match between study and test, which boosted memory performance, took place on trials testing the arousing words than on those testing the neutral words.

\section{EXPERIMENT 4}

In Experiments 1-3, we examined memory for words at the visual field periphery, which were either neutral or arousing. These words were presented with either neutral (Experiments 1 and 2) or arousing (Experiment 3) words at fixation. In Experiment 4, we asked whether the difference in forgetting rates, found in Experiments 1 and 2 for peripheral arousing and neutral words, would originate only when arousal differences were due to properties of the actual peripheral stimuli, or whether such differences would be found on the basis of arousal changes in the central stimuli. In Experiment 4, we studied memory for neutral words presented in the periphery, when either a neutral or arousing word was presented at the center of the screen.

The design of Experiment 4 was analogous to those of previous studies examining memory for visually peripheral details of an arousing event. These studies ordinarily place either an arousing or a neutral stimulus in the center of the visual field and a neutral stimulus in the periphery (e.g., Burke et al., 1992; Christianson, 1984; Christianson \& Loftus, 1991; Wessel et al., 2000). Some of these studies, in accord with Easterbrook's (1959) "narrowing of attention" hypothesis, have reported impaired memory for peripheral information in the arousing trials, compared with the neutral trials (Christianson \& Loftus, 1991; Loftus et al., 1987). However, others have not found such an impairment (e.g., Wessel et al., 2000) - including a study in which eye fixation was controlled by brief exposure times (Christianson et al., 1991). All of these studies tested memory only immediately after encoding. One exception is the study by Burke et al. that examined memory for such details both immediately and after a delay. They found an initial disadvantage for memory of peripheral details in the arousing condition versus the neutral condition, which decreased at delayed test.

\section{Method}

Participants. The participants were 50 undergraduates at New York University ( 31 females and 19 males between 18 and 28 years of age) assigned to either the immediate test condition $(n=25)$ or delayed test condition $(n=25)$.

Materials. Materials were the same as in Experiments 1, 2, and 3.

Design and Procedure. The method for Experiment 4 was identical to that of Experiment 1 except for two changes. First, at the center either an arousing word ( 8 trials) or a neutral word ( 8 trials) was presented (rather than only neutral words, as in Experiments 1 and 2, or only arousing words as in Experiment 3). Second, in the periphery only neutral words were presented (rather than either neutral or arousing as in Experiments 1, 2, and 3).
As in the previous experiments, recognition of central words was found to be at ceiling both at the immediate (99\%) and delayed $(99 \%)$ tests, suggesting that the participants were indeed engaged with the central task. Recognition scores of 4 participants who recognized fewer than 14 of the $16(87.5 \%)$ central words correctly were not used (see Method section of Experiment 1 for reasoning).

\section{Results}

Data analysis was the same as that in Experiment 1 (see Results section of Experiment 1).

There was no interaction of arousal condition $\times$ retention interval. The $95 \%$ confidence intervals for recognition rates at the immediate test for neutral peripheral words presented both in the arousing condition $\left(\mu_{\text {lower }}=54.87 \%\right)$ and neutral condition $\left(\mu_{\text {lower }}=55.18 \%\right)$ show that these rates were significantly different from chance $(50 \%)$, but they were not significantly different from chance at the delayed test $\left(\mu_{\text {lower }}=47.37 \%\right.$ and $\mu_{\text {lower }}=44.18 \%$, respectively). All pairwise comparisons were found to be not significant.

\section{Discussion}

In contrast to Experiments 1 and 2, Experiment 4 did not reveal an interaction of arousal condition $\times$ retention interval (see Figure 5), nor were recognition rates for words in the arousing versus neutral conditions found to differ at delayed test. These results suggest that the different forgetting rates for arousing and neutral stimuli apparent in Experiments 1 and 2 occur only when arousal differences are due to properties of the word tested, and not when arousal conditions differ due to elements outside this stimulus, as when the arousal was due to the central word.

Presenting either a neutral or an arousing word in the center of the screen did not have a significant influence on memory of the neutral peripheral word. These findings are consistent with previous studies, which have reported no decrement for memory of neutral peripheral details for arousing versus neutral conditions (Wessel et al., 2000) when overt attention is controlled (Christianson et al., 1991).

\section{GENERAL DISCUSSION}

Arousal may enhance memory by affecting perception and attention during encoding (Christianson \& Loftus, 1991; Reisberg \& Heuer, 1992) and by altering memory retention (Kleinsmith \& Kaplan, 1963; McGaugh, 2000). In this study, we attempted to examine the influence of arousal on memory, while minimizing the selective modulation of attention by arousal. The main finding from our study is that arousal can facilitate slower forgetting, even when overt attention is not focused on the arousing stimulus. Whereas recognition of neutral words became worse over time, recognition of arousing words either stayed the same or showed improvement. A reliable word type (arousing vs. neutral) $\times$ retention interval crossover 


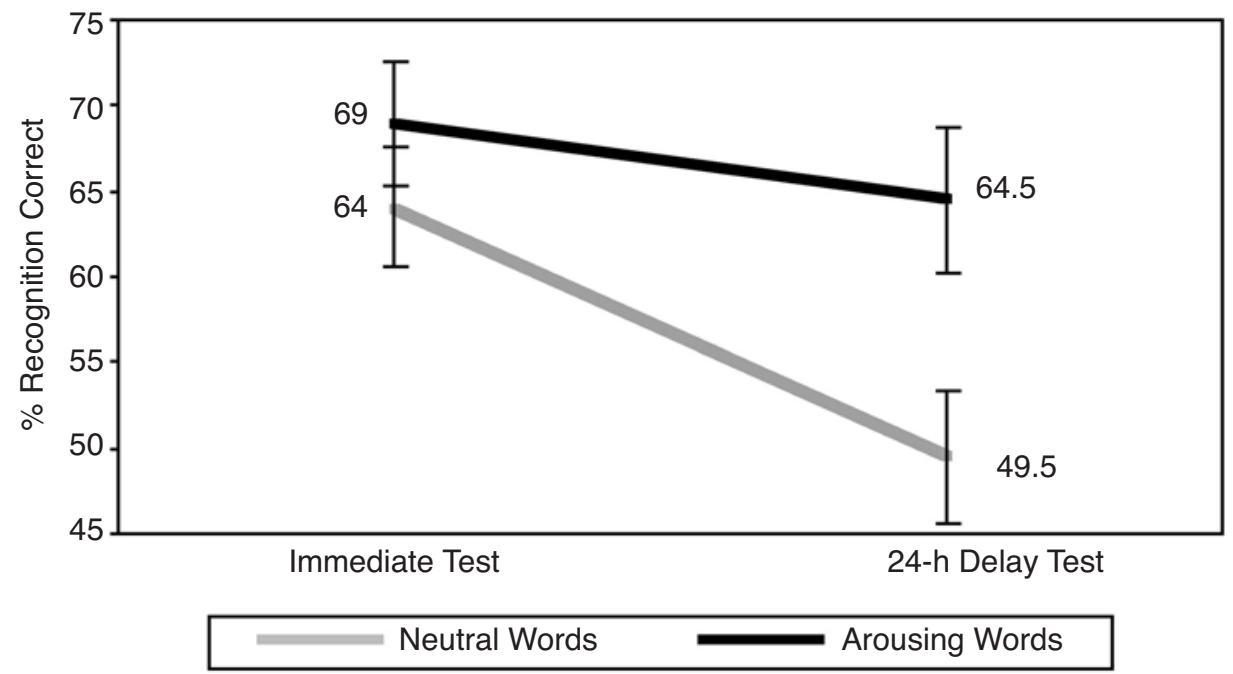

Figure 4. Experiment 3: Recognition rates for peripheral words at immediate and delayed tests. One word (either neutral or arousing) was presented at the periphery at the same time as an arousing word was presented at the center of the screen. Brackets represent standard errors of the means.

interaction, like that reported by Kleinsmith and Kaplan, emerged for the results of Experiments 1 and 2. Results from Experiments 1-3 show that at the delayed test, peripheral arousing words were remembered better than peripheral neutral words. Better memory for arousing words than for nonarousing words was evident only at delayed test, supporting the notion that this result was primarily due to an effect of slower forgetting. Had there been any possible confounding properties of the stimuli such as imageability, concreteness, or frequency underlying these results, one would have expected to see superior memory for arousing stimuli compared with nonarousing stimuli at immediate test. However, such a difference was not observed.

Also, in accord with past studies reporting no difference for memory of neutral peripheral details for arousing versus neutral conditions (Christianson et al., 1991; Wessel et al., 2000), and contrary to the predictions of the "narrowing of attention" theory (Easterbrook, 1959), presenting either a neutral or an arousing word at the focus of attention in Experiment 4 did not alter memory of the neutral words at the visual field periphery. The implications of this result, as well as those of findings from Experiments 1-3, for theories of the effects of arousal on

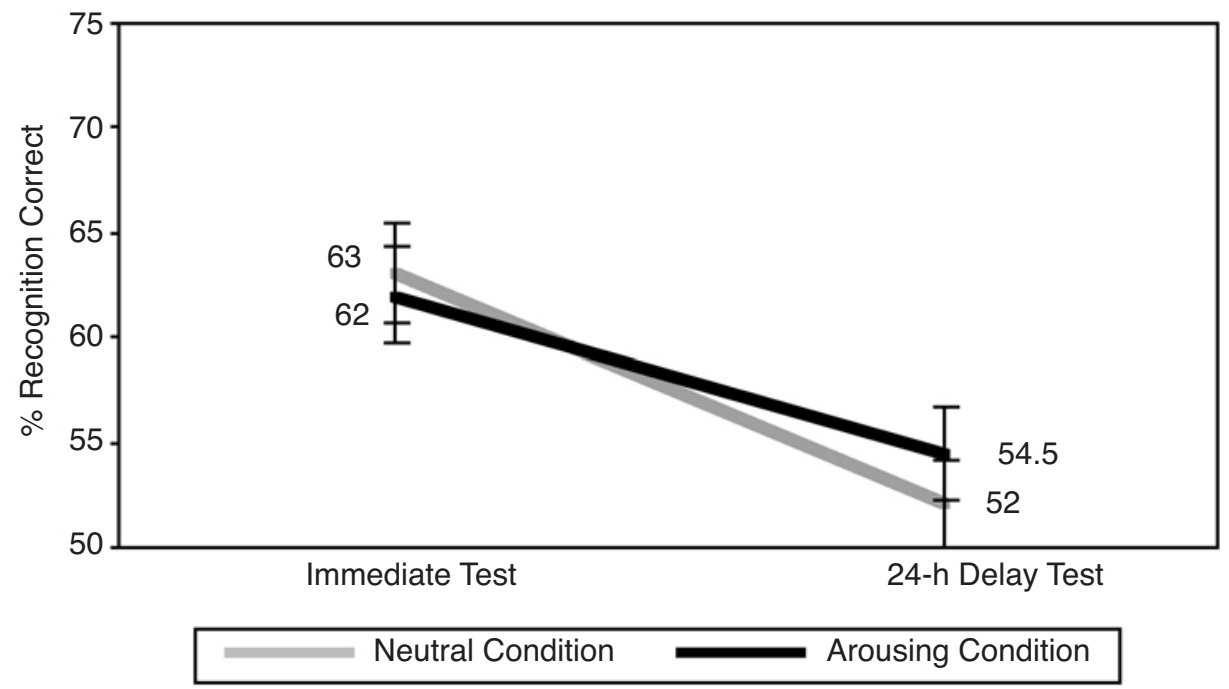

Figure 5. Experiment 4: Recognition rates for peripheral words at immediate and delayed tests. A neutral word was presented at the periphery at the same time as either a neutral or an arousing word was presented at the center of the screen. Brackets represent standard errors of the means. 
attention and consolidation are considered below, following a discussion of the effects of arousal on the rate of forgetting and on word recognition at the immediate test.

\section{Effects of Arousal on the Rate of Forgetting}

Consistent with previous findings, indicating that arousing stimuli are retained better than nonarousing stimuli (e.g., Cahill et al., 1996; Canli, Desmond, Zhao, \& Gabrieli, 2002), data from Experiments 1-3 revealed that whereas recognition for neutral words decreased over time, recognition for arousing words remained unchanged. After a delay, arousing words were recognized better than neutral words. These results go beyond those of previous studies in indicating that slower forgetting of arousing words occurs even when that stimulus is presented in the visual field periphery.

We suggest that one can account for these findings by referring to theories of enhanced memory consolidation for arousing stimuli (McGaugh, 1992). Different physiological systems, including those involved in the discharge of hormones believed to affect memory consolidation (Buchanan \& Lovallo, 2001; Cahill, 1997; McGaugh, 2000), become active during, and closely following, the occurrence of arousing events. The influence of arousal on enhanced memory consolidation will become evident only after a delay, as consolidation of memory happens over time. If memory for arousing stimuli were affected by arousal, solely by way of strengthening consolidation, we would anticipate better memory for such stimuli relative to neutral stimuli after a delay, but not immediately after encoding. These indeed were our observations.

There are two alternative interpretations of our findings. One is that differential covert shifts of attention in favor of the arousing words may have facilitated the processing of those words. Although in Experiment 2 we attempted to minimize differential covert shifts of attention by simultaneously exposing participants to both an arousing word and a neutral word at the periphery, we do not claim to have eliminated any possible influence of such selective shifts on performance. A second alternative hypothesis relates to the level-of-processing framework (Craik \& Lockhart, 1972). According to such an interpretation, although the attentional resources allocated to each word type in this paradigm may be similar, a more elaborate encoding of the arousing words could lead to enhanced long-term memory. However, both of these alternative hypotheses would predict better memory for arousing words than for neutral words both at the immediate test and at the delayed test. It is possible that some type of inhibition or interference effect was present at the immediate test for the arousing words, lowering accuracy rates. Possible interference effects at the immediate test are discussed in the next section.

The differences in forgetting rates (Experiments 1-2) and the differences in recognition rates at the delayed test (Experiments 1-3) for neutral and arousing peripheral words do not occur when arousal conditions differ because of the central word, rather than the tested peripheral word. This is implied by the results of Experiment 4, which do not reveal any differences in recognition rates for neutral peripheral words presented with either an arousing or a nonarousing word as the focus of attention, suggesting that the results of Experiments 1-3 are stimulus specific and that in this paradigm a general arousal state does not facilitate retention of nonarousing stimuli. This notion is also supported by the results of Experiment 3 , in which presenting an emotional word in the center of the screen did not seem to facilitate forgetting rates for the neutral peripheral words. Furthermore, in Experiment 2 a peripheral neutral word was presented together with a peripheral arousing word on each trial, but a fast forgetting rate for the former was none the less observed.

\section{Effects of Arousal on Recognition at the Immediate Test}

In all four experiments, no significant difference was found between recognition rates for arousing and nonarousing words at the immediate test. However, a trend was revealed of poorer recognition rates at the immediate test for arousing words than for neutral words, when data from Experiments 1 and 2 were collapsed. Although this effect is weak, it is consistent with the initial report of Kleinsmith and Kaplan (1963) and with later replications of this finding (e.g., Baddeley, 1982; Levonian, 1966; Walker \& Tarte, 1963). Kleinsmith and Kaplan accounted for their counterintuitive result by referring to Walker's (1958) "action-decrement" consolidation theory. The action decrement is a refractory state that follows performance of a response, correlating with the amount of learning that has accumulated to that same response over time. The superior consolidation due to high arousal is advantageous over time, but it produces a more intense refractory state in immediate tests. Thus, information learned under high arousal is relatively inaccessible at early test.

Another explanation for Kleinsmith and Kaplan's (1963) finding was put forward by Revelle and Loftus's "tick-rate hypothesis" (Revelle, 1989; Revelle \& Loftus, 1990). Revelle and Loftus suggest that arousal increases the rate at which a scene is sampled, interfering with accessibility in immediate memory. However, an increase in the rate at which the to-be-learned material is linked with internal and external context may also aid long-term retrieval. In our experiments, differential sampling rates are believed to be minimized by brief stimulus exposure. Thus, although differential sampling rates may carry some weight, it seems that this account cannot provide a congruous interpretation for this portion of our results. A recent study also suggests that decrements in immediate memory for stimuli preceding emotional items are linked to amygdala-dependent $\beta$-adrenergic modulation of episodic encoding (Strange, Hurlemann, \& Dolan, 2003).

The results of some studies (Doerksen \& Shimamura, 2001) imply that the lack of memory enhancement by arousal at immediate test may be specific to cued recall and recognition tests (Richardson, Strange, \& Dolan, 2004) rather than to free recall (Strange, Henson, Friston, $\&$ Dolan, 2000). To date, the specific neural and cognitive mechanisms underlying the decrement for immediate 
recognition of arousing stimuli and of items associated with arousing stimuli are far from apparent, and further research is needed before they can be fully understood.

To summarize the effects of arousal on immediate recognition, results from all four experiments suggest that when overt attention is not focused on the to-beremembered word, arousal does not influence immediate memory for that stimulus to a significant degree. It is possible that any facilitating effect of arousal on memory may have been shadowed at the immediate test by a general inhibition or interference effect (Revelle \& Loftus, 1990; Walker, 1958), thereby making recognition of arousing words seem impaired, or equal to recognition of neutral words. Such inhibition processes may have also contributed to the trend observed in the combined results of Experiments 1 and 2 of an increase in memory for arousing words over a delay. To better understand the processes involved in immediate recognition of arousing words, further work must be done. One should note that in the present paradigm, an interval spanning a few minutes was introduced between encoding and test, so the earliest effects of arousal on memory and attention are not examined here.

\section{Implication for Theories Regarding the Effects of Arousal on Attention and Memory Storage}

To specifically examine changes to the selectivity of attention by arousal in our paradigm, we conducted Experiment 4 , in which we presented an arousing stimulus in the center of the screen. According to Easterbrook's (1959) proposal, which states that arousal will lead to the "narrowing of attention," and thus impair encoding of peripheral details, one would expect to find inferior recognition for neutral peripheral words presented with central arousing words than for those presented with central nonarousing words. However, in Experiment 4, memory for the peripheral neutral words did not differ with the arousing properties of the central word. The results allude to one of two options: Either the selectivity of attention did not vary to a significant degree by altering the arousing properties of the central word, or alternatively such changes did not have a significant effect on memory for the peripheral words. The results are consistent with those of previous studies reporting no difference for memory of neutral peripheral details of picture slides displayed in either arousing or neutral conditions (Wessel et al., 2000) when presentation was brief (Christianson et al., 1991). This pattern of findings holds for both recall (Christianson et al., 1991; Wessel et al., 2000) and recognition (Christianson et al., 1991) tests.

Our results do not imply that the effects of arousal on attention cannot significantly influence memory for arousing events. Rather, we propose that when the modulation of attention by arousal is minimized, slower forgetting rates will still be facilitated by arousal. A relative memory decrement for periphery-neutral items in the arousing condition might have been evident if the trial duration had been longer.
By looking at memory of emotional material under conditions that manipulate attention, immediately after encoding as well as after a delay, we can offer support for a more precise link between memory enhancement of arousing material and modulation of hippocampal-dependent memory consolidation in humans. The results indicate for the first time that arousal can support slower rates of forgetting even when the difference in attentional resources allocated to the arousing and nonarousing stimulus is minimized. Although memory of arousing stimuli is most likely enhanced by both modulation of acquisition (Anderson \& Phelps, 2001; Christianson \& Loftus, 1991) and mediation of memory retention (Cahill et al., 1995; LaBar $\&$ Phelps, 1998), our data imply that when the effect of arousal on attention is manipulated, modulation of memory retention is sufficient to enhance memory of arousing stimuli in humans.

\section{REFERENCES}

Adolphs, R., Denburg, N. L., \& Tranel, D. (2001). The amygdala's role in long-term declarative memory for gist and detail. Behavioral Neuroscience, 115, 983-992.

AdolPhs, R., Tranel, D., \& Denburg, N. L. (2000). Impaired emotional declarative memory following unilateral amygdala damage. Learning \& Memory, 7, 180-186.

Anderson, A. K., \& Phelps, E. A. (2001). Lesions of the human amygdala impair enhanced perception of emotionally salient events. $\mathrm{Na}$ ture, 411, 305-309.

BADDELEY, A. D. (1982). Implications of neuropsychological evidence for theories of normal memory. Philosophical Transactions of the Royal Society of London: Series B, 298, 59-72.

Balch, W. R., Myers, D. M., \& PAPOTtO, C. (1999). Dimensions of mood in mood-dependent memory. Journal of Experimental Psychology: Learning, Memory, \& Cognition, 25, 70-83.

Balota, D. A., Pilotti, M., \& Cortese, M. J. (2001). Subjective frequency estimates for 2,938 monosyllabic words. Memory \& Cognition, 29, 639-647.

Bargh, J. A., Chaiken, S., Govender, R., \& Pratto, F. (1992). The generality of the automatic attitude activation effect. Journal of Personality \& Social Psychology, 62, 893-912.

BoHANNON, J. N., III (1988). Flashbulb memories for the space shuttle disaster: A tale of two theories. Cognition, 29, 179-196.

Bradley, M. M., Greenwald, M. K., Petry, M. C., \& Lang, P. J. (1992). Remembering pictures: Pleasure and arousal in memory. Journal of Experimental Psychology: Learning, Memory, \& Cognition, 18, 379-390.

BUCHANAN, T. W., \& Lovallo, W. R. (2001). Enhanced memory for emotional material following stress-level cortisol treatment in humans. Psychoneuroendocrinology, 26, 307-317.

Burke, A., Heuer, F., \& Reisberg, D. (1992). Remembering emotional events. Memory \& Cognition, 20, 277-290.

CAHILL, L. (1997). The neurobiology of emotionally influenced memory: Implications for understanding traumatic memory. In R. Yehuda \& A. C. McFarlane (Eds.). Psychobiology of posttraumatic stress disorder (Annals of the New York Academy of Sciences, Vol. 821, pp. 238-246). New York: New York Academy of Sciences.

CAHILl, L., \& AlkiRe, M. T. (2003). Epinephrine enhancement of human memory consolidation: Interaction with arousal at encoding. Neurobiology of Learning \& Memory, 79, 2194-2198.

Cahill, L., Babinsky, R., Markowitsch, H. J., \& McGaugh, J. L. (1995). The amygdala and emotional memory. Nature, 377, 295-296.

CAHILl, L., GorsKi, L., \& Le, K. (2003). Enhanced human memory consolidation with post-learning stress: Interaction with the degree of arousal at encoding. Learning \& Memory, 10, 4270-4274.

Cahill, L., Haier, R. J., Fallon, J., Alkire, M. T., Tang, C., 
Keator, D., Wu, J., \& McGaugh, J. L.(1996). Amygdala activity at encoding correlated with long-term, free recall of emotional information. Proceedings of the National Academy of Sciences, 93, 8016-8021.

CaHILl, L., Prins, B., Weber, M., \& McGaUgh, J. L. (1994). Beta-adrenergic activation and memory for emotional events. Nature, 20, 702-704.

Canli, T., Desmond, J. E., Zhao, Z., \& Gabrieli, J. D. (2002). Sex differences in the neural basis of emotional memories. Proceedings of the National Academy of Science, 99, 10789-10794.

CARPENTER, R. H. S. (1988). Movements of the eyes. London: Pion Press.

Christianson, S. A. (1984). The relationship between induced emotional arousal and amnesia. Scandinavian Journal of Psychology, 25, 147-160.

Christianson, S. A. (1992). Remembering emotional events: Potential mechanisms. In S. Christianson (Ed.), The handbook of emotion and memory: Research and theory (pp. 307-340). Hillsdale, NJ: Erlbaum.

Christianson, S. A., \& Fallman, L. (1990). The role of age on reactivity and memory for emotional pictures. Scandinavian Journal of Psychology, 31, 291-301.

Christianson, S. A., \& LofTus, E. F. (1991). Remembering emotional events: The fate of detailed information. Cognition \& Emotion, 5, 81-108.

Christianson, S. A., Loftus, E. F., Hoffman, H., \& Loftus, G. R. (1991). Eye fixations and memory for emotional events. Journal of Experimental Psychology: Learning, Memory, \& Cognition, 17, 693-701.

Clifford, B., \& Hollins, C. (1981). Effects of the type of incident and the number of perpetrators on eyewitness memory. Journal of Applied Psychology, 66, 364-370.

Craik, F. I. M., \& LockHART, R. S. (1972). Levels of processing: A framework for memory research. Journal of Verbal Learning \& Verbal Behavior, 11, 671-684.

Doerksen, S., \& Shimamura, A. P. (2001). Source memory enhancement for emotional words. Emotion, 1, 5-11.

Dolan, R. J., Lane, R., Chua, P., \& Fletcher, P. (2000). Dissociable temporal lobe activations during emotional episodic memory retrieval. NeuroImage, 11, 203-209.

EASTERBROOK, J. A. (1959). The effect of emotion on cue utilization and the organization of behavior. Psychology Review, 66, 183-201.

Fox, E., Russo, R., Bowles, R., \& Dutton, K. (2001). Do threatening stimuli draw or hold visual attention in subclinical anxiety? Journal of Experimental Psychology: General, 130, 681-700.

GALLAGHER, M., \& KAPP, B. S. (1981). Effect of phentolamine administration into the amygdala complex of rats on time-dependent memory processes. Behavioral \& Neural Biology, 31, 90-95.

Gernsbacher, M. A. (1984). Resolving twenty years of inconsistent interactions between lexical familiarity and orthography, concreteness, and polysemy. Journal of Experimental Psychology: General, 113, 256-281.

GILHOOLY, K. J., \& LoGIE, R. H. (1980). Age-of-acquisition, imagery, concreteness, familiarity, and ambiguity measures for 1,944 words. Behavior Research Methods \& Instrumentation, 12, 395-427.

Hamann, S. B., Ely, T. D., Grafton, S. T., \& Kilts, C. D. (1999). Amygdala activity related to enhanced memory for pleasant and aversive stimuli. Nature Neuroscience, 2, 289-293.

Hansen, C. H., \& Hansen, R. D. $(198 \overline{8})$. Finding the face in the crowd: An anger superiority effect. Journal of Personality \& Social Psychology, 54, 917-924.

HEUER, F., \& REISBERG, D. (1990). Vivid memories of emotional events: The accuracy of remembered minutiae. Memory \& Cognition, 18, 496 506.

Hochberg, J. (1978). Perception (2nd ed.). Englewood Cliffs, NJ: Prentice-Hall.

KePPEL, G. (1991). Design and analysis: A researcher's handbook (3rd ed.). Englewood Cliffs, NJ: Prentice-Hall.

Kleinsmith, L. J., \& KaPlan, S. (1963). Paired-associate learning as a function of arousal and interpolated interval. Journal of Experimental Psychology, 65, 190-193.

La Bar, K. S., LeDoux, J. E., Spencer, D. D., \& Phelps, E. A. (1995). Impaired fear conditioning following unilateral temporal lobectomy in humans. Journal of Neuroscience, 15, 6846-6855.

LaBAR, K. S., \& Phelps, E. A. (1998). Arousal-mediated memory consolidation: Role of the medial temporal lobe in humans. Psychological Science, 9, 490-493.
LEvonian, E. (1966). Evoked potential in relation to subsequent alpha frequency. Science, 152, 1280-1282.

Liang, K. C., Juler, R. G., \& McGaugh, J. L. (1986). Modulating effects of posttraining epinephrine on memory: Involvement of the amygdala noradrenergic system. Brain Research, 12, 125-133.

Libkuman, T. M., Nichols-Whitehead, P., GrifFith, J., \& Thomas, R. (1999). Source of arousal and memory for detail. Memory \& Cognition, 27, 166-190.

Loftus, E. F., Loftus, G. R., \& Messo, J. (1987). Some facts about weapon focus. Law \& Human Behavior, 11, 55-62.

Mayfrank, L., Kimmig, H., \& Fischer, B. (1987). The role of attention in the preparation of visually guided saccadic eye movements in man. In J. K. O'Regan \& A. Levy-Schoen (Eds.), Eye movements: From physiology to cognition (pp. 37-45). New York: Elsevier, North-Holland.

McGAUGH, J. L. (1992). Affect, neuromodulatory systems and memory storage. In S. Christianson (Ed.), The handbook of emotion and memory: Research and theory (pp. 269-288). Hillsdale, NJ: Erlbaum.

McGaUgh, J. L. (2000). Memory: A century of consolidation. Science, 14, 248-251.

NEISSER, U. (1976). Cognition and reality. New York: Freeman.

OCHSNER, K. N. (2000). Are affective events richly recollected or simply familiar? The experience and process of recognizing feelings past. Journal of Experimental Psychology. General, 129, 242-261.

Öhman, A., Estevens, F., \& Sonres, F. (1995). Prepare dness and preattentive associative learning: Electrodermal conditioning masked stimuli. Journal of Psychophysiology, 9, 99-108.

Packard, M. G., \& Teather, L. A. (1998). Amygdala modulation of multiple memory systems: Hippocampus and caudate-putamen. Neurobiology of Learning \& Memory, 69, 163-203.

Reisberg, D., \& Heuer, F. (1992). Remembering the details of emotional events. In E. Winograd \& U. Neisser (Eds.), Affect and accuracy in recall: Studies of "flashbulb" memories (pp. 163-190). Cambridge, MA: Harvard University Press.

Revelle, W. (1989). Personality, motivation, and cognitive performance. In P. Ackerman, R. Kanfer, \& R. Cudeck (Eds.), Learning and individual differences: Abilities, motivations, and methodology (pp. 297-341). Hillsdale, NJ: Erlbaum.

Revelle, W., \& Loftus, D. A. (1990). Individual differences and arousal: Implications for the study of mood and memory. Cognition \& Emotion, 4, 209-237.

Richardson, M. P., Strange, B. A., \& Dolan, R. J. (2004). Encoding of emotional memories depends on amygdala and hippocampus and their interactions. Nature Neuroscience, 7, 278-285.

Strange, B. A., Henson, R. N., Friston, K. J., \& Dolan, R. J. (2000). Brain mechanisms for detecting perceptual, semantic, and emotional deviance. NeuroImage, 12, 425-433.

Strange, B. A., HURlemanN, R., \& Dolan, R. J. (2003). An emotioninduced retrograde amnesia in humans is amygdala- and betaadrenergic-dependent. Proceedings of the National Academy of Sciences, 100, 13626-13631.

VAZDARJANOVA, A., \& MCGAUGH, J. L. (1999). Basolateral amygdala is involved in modulating consolidation of memory for classical fear conditioning. Journal of Neuroscience, 1, 6615-6622.

Venables, P. H., \& Christie, M. J. (1973). Mechanisms, instrumentation, recording techniques, and quantification of responses. In W. F. Prokasy \& D. C. Raskin (Eds.), Electrodermal activity in psychological research (pp. 125-155). New York: Academic Press.

Vuilleumier, P., Armony, J. L., Driver, J., \& Dolan, R. J. (2001). Effects of attention and emotion on face processing in the human brain: An event-related fMRI study. Neuron, 30, 829-841.

Vuilleumier, P., \& Schwartz, S. (2001). Emotional facial expressions capture attention. Neurology, 23, 153-158.

WALKER, E. L. (1958). Action decrement and its relation to learning. Psychological Review, 65, 129-142.

WALKER, E. L., \& TARTE, R. D. (1963). Memory storage as a function of arousal and time with homogeneous and heterogeneous lists. Journal of Verbal Learning \& Verbal Behavior, 2, 113-119.

Wessel, I., van der KoOy, P., \& Merckelbach, H. (2000). Differential recall of central and peripheral details of emotional slides is not a stable phenomenon. Memory, $\mathbf{8}, \underline{95-109}$. 
APPENDIX

Words and Their Position on the Screen in Experiments 1-4

\begin{tabular}{|c|c|c|c|c|c|c|c|c|c|c|c|}
\hline \multicolumn{3}{|c|}{ Experiment 1} & \multicolumn{3}{|c|}{ Experiment 2} & \multicolumn{3}{|c|}{ Experiment 3} & \multicolumn{3}{|c|}{ Experiment 4} \\
\hline Word & Position & Foil & Word & Position & Foil & Word & Position & Foil & Word & Position & Foil \\
\hline truck & center & clam & truck & center & clam & pussy & center & sex & rape & center & fail \\
\hline aunt & center & wire & aunt & center & wire & murder & center & kill & orgasm & center & herpes \\
\hline fork & center & eagle & fork & center & eagle & orgy & center & fuck & cancer & center & penis \\
\hline solar & center & patrol & solar & center & patrol & death & center & tits & vagina & center & lust \\
\hline radio & center & field & radio & center & field & tumor & center & whore & vomit & center & suffer \\
\hline league & center & omelet & league & center & omelet & cock & center & tragic & homo & center & suicide \\
\hline jacket & center & dates & jacket & center & dates & evil & center & pain & fear & center & hell \\
\hline desk & center & shade & desk & center & shade & $\sin$ & center & rage & slut & center & fire \\
\hline encil & center & face & & & & terror & center & slave & fork & center & eagle \\
\hline fabric & center & owner & & & & panic & center & crisis & solar & center & patrol \\
\hline fence & center & bass & & & & guilt & center & hurt & inch & center & logic \\
\hline hangar & center & memory & & & & stab & center & crash & face & center & pencil \\
\hline $\operatorname{logic}$ & center & inch & & & & cunt & center & incest & fabric & center & owner \\
\hline scanner & center & ruler & & & & fail & center & dick & hangar & center & memory \\
\hline thumb & center & cafe & & & & angry & center & misery & thumb & center & cafe \\
\hline beard & center & layer & & & & horror & center & scream & beard & center & layer \\
\hline canvas & periphery & orange & canvas & periphery & orange & canvas & periphery & orange & canvas & periphery & orange \\
\hline pond & periphery & bar & pond & periphery & bar & pond & periphery & bar & league & periphery & omelet \\
\hline cancer & periphery & penis & cancer & periphery & penis & cancer & periphery & penis & fence & periphery & bass \\
\hline & periphery & vagina & lust & periphery & vagina & lust & periphery & vagina & scanner & periphery & ruler \\
\hline fear & periphery & hell & fear & periphery & hell & fear & periphery & hell & desk & periphery & shade \\
\hline slut & periphery & fire & slut & periphery & fire & slut & periphery & fire & pond & periphery & bar \\
\hline note & periphery & eraser & note & peri & eraser & note & periphery & eraser & note & periphery & eraser \\
\hline carrot & periphery & apple & carrot & peri & apple & carrot & periphery & apple & carrot & periphery & apple \\
\hline vomit & periphery & suffer & vomit & peri & suffer & vomit & periphery & suffer & truck & periphery & clam \\
\hline homo & hery & suicide & homo & hery & suicide & homo & periphery & suicide & aunt & periphery & wire \\
\hline plate & pe & lever & plate & pe & lever & plate & peri & lever & plate & periphery & lever \\
\hline clock & periphery & wagon & clock & periphery & wagon & clock & periphery & wagon & clock & periphery & wagon \\
\hline rape & periphery & fail & rape & periphery & fail & rape & periphery & hate & radio & periphery & field \\
\hline orgasm & periphery & herpes & orgasm & periphery & herpes & orgasm & periphery & herpes & jacket & periphery & dates \\
\hline flag & phery & point & flag & periphery & point & flag & periphery & point & flag & periphery & point \\
\hline once & periphery & math & once & periphery & math & once & periphery & math & once & periphery & math \\
\hline
\end{tabular}

Note-In Experiments 1 and 2, center words are neutral, and peripheral words are neutral/arousing. In Experiment 3, center words are arousing, and peripheral words are neutral/arousing. In Experiment 4, center words are neutral/arousing, and peripheral words are neutral.

(Manuscript received December 29, 2003;

revision accepted for publication March 26, 2004.) 